\title{
Effect of Three Calmodulin Antagonists on Subpopulations of CD44/CD24 Immunophenotypes in Breast Cancer Cell Lines
}

\author{
Abdulwahab Noor Wali ${ }^{1}$, Mohammed Farouk El Shal ${ }^{2}$, Mayson H Alkhatib ${ }^{2 \star}$ and \\ Laila A Damiati ${ }^{3}$ \\ ${ }^{1}$ Department of Clinical Biochemistry, Faculty of Medicine, ${ }^{2}$ Department of Biochemistry, Faculty of Science, King Abdulaziz \\ University, Jeddah, ${ }^{3}$ Stem Cell Unit, King Fahd Medical Research Center, Jeddah, Saudi Arabia
}

*For correspondence: Email: mhalkhatib@kau.edu.sa; Tel: +966599240526; Fax: + 96626400376

\begin{abstract}
Purpose: To determine the effect of three calmodulin antagonists (A-7, $W-7$ and $W-13)$ on the subpopulations of CD44/CD24 immunophenotypes in MDA-MB-231 and MDA-MB-468 breast cancer cell lines.

Methods: Flow cytometry analysis was used to determine the proportion of the various subpopulations of the immunophenotypes, viz, CD44+CD24-, CD44-CD24+ and CD44+CD24+, when MDA-MB-231 and MDA-MB-468 cells were subjected to calmodulin antagonists. The effect of $W-13$ on the invasion properties of $M D A-M B-231$ and $M D A-M B-468$ was investigated using Matrigel invasion assay.

Results: $A-7, W-7$ and $W-13$ caused alterations in the subpopulation of CD44+CD24- in MDA-MB-231 cells. The most potent antagonist was $W-13$ as it reduced the proportion of tumorigenic $C D 44+C D 24-$ to $0.64 \pm 0.05$ at a concentration of $80 \mu \mathrm{M}$. In contrast, the subpopulation of MDA-MB-468 cells, which had a low fraction of CD44+CD24-, was not altered when administered with $W-7$ but showed variations when incubated with $W$-13. Specifically, when the concentration of $W$-13 increased from $20-100 \mu M$, the proportion of $C D 44+C D 24+$ was reduced from $92.93 \pm 3.2$ to $60.96 \pm 2.4$. The effect of $W-13$ on the subpopulations of CD44+CD24- and CD44+CD24+ in MDA-MB-231 and MDA-MB-468, respectively, reduced the invasion properties of the cells.

Conclusion: The calmodulin antagonist, $W-13$, has a significant antitumor effect on MDA-MB-231 and MDA-MB-468 breast cancer cells.
\end{abstract}

Keywords: Calmodulin antagonists; Flow cytometry; Invasion assay; Immunophenotypes

Tropical Journal of Pharmaceutical Research is indexed by Science Citation Index (SciSearch), Scopus, International Pharmaceutical Abstract, Chemical Abstracts, Embase, Index Copernicus, EBSCO, African Index Medicus, JournalSeek, Journal Citation Reports/Science Edition, Directory of Open Access Journals (DOAJ), African Journal Online, Bioline International, Open-J-Gate and Pharmacy Abstracts

\section{INTRODUCTION}

Breast cancer cells have been reported to contain more than one immunophenotype subpopulations that have different invasive properties and roles in tumorigenicity [1,2]. They were distinguished according to the expression level of two glycoproteins on the surface of the cells, CD44 and CD24, markers of breast cancer cell phenotype since CD44 binds E-selectin and CD24 is known to be attached to P-selectin [3,4]. Cells with high levels of CD44 and low level of CD24 (CD44 + CD24-) were identified as cancer stem cells that have the ability to self-renew and differentiate. In spite of the arguable clinical significance of CD44+CD24-, they have been associated with distant metastasis and unfortunate survival [5]. 
CD44 is a ubiquitous multi-structural and multifunctional cell surface glycoprotein involved in adhesive cell-cell and cell-matrix interactions, and cell migration and cell homing.

A previous study reported that by ectopically overexpressing a splice variant of CD44, it was enough for a non-metastatic rat glioma cell line to attain metastatic properties [6]. The variant isoforms of CD44 have showed antiproliferative and apoptotic effect $[7,8]$.

While CD44 is associated with stem cell-like cancer cells, CD24 is correlated with either luminal or basal breast cancer cells [9]. In the presence of high proportions of CD24+, the luminal cells are likely to exist whereas the basal cells are expressed at higher percentages of CD24-.

Several compounds have been tested for inhibiting CD44 such as the calcium-modulated protein (calmodulin) antagonists (chlorpromazine, trifluoperazine, W-7) and the calcium blocker verapamil [10]. However, the study did not test the effect of these compounds on breast cancer stem cells. It is not known, however, whether targeting CD44 can alter the fate of cancer stem cells themselves. In this study, the effect of the calmodulin antagonists ( $\mathrm{N}-(10-$ Aminodecyl)-5-chloro-1-naphthalenesulfonamide hydrochloride (A-7), N-(6-Aminohexyl)-5-chloro1-naphthalenesulfonamide hydrochloride (W-7) and $\mathrm{N}$-(4-Aminobutyl)-5-chloro-2-naphthalenesulfonamide hydrochloride (W-13)) on MDA-MB231 and MDA-MB-468 breast cancer cell lines was investigated.

\section{EXPERIMENTAL}

\section{Materials and cell lines}

Monoclonal antibodies against human CD44 (FITC; cat. \#555478) and CD24 (PE; cat. \#555428) were obtained from BD Biosciences (San Diego, CA, USA). The breast cancer cell lines (MDA-MB-231 and MDA-MB-468) were obtained from American Type Tissue Culture Collection (Manassas, VA, USA).

\section{Flow cytometric analysis of cancer stem cells subjected to A-7, W-7 and W-13}

Cells were cultured and incubated in different concentrations of A-7, W-7 and W-13 for 24 hours as described elsewhere [11]. Cells were washed once with phosphate-buffered saline (PBS) and then harvested with $0.05 \%$ trypsin/0.025\% ethylenediaminetetraacetic acid (EDTA). Detached cells were washed with PBS containing $1 \%$ fetal calf serum and $1 \%$ penicillin/streptomycin (washing buffer), and resuspended in the wash buffer (106 cells/100 $\mu \mathrm{L})$. Combinations of fluorochrome-conjugated monoclonal antibodies against human CD44 and CD24 or their respective isotype controls were added to the cell suspension at concentrations recommended by the manufacturer and incubated at $4{ }^{\circ} \mathrm{C}$ in the dark for 30 to $40 \mathrm{~min}$. The labeled cells were washed in the wash buffer, and then were analyzed using the flow cytometry.

\section{Matrigel invasion assay}

The invasion assay was performed as recommended by the manufacturer of the invasion assay kit (\#ECM554; Chemicon International, Temecula, CA, USA). Briefly, cells were serum starved and incubated for $24 \mathrm{~h}$. The 50,000 cells were placed on the top insert with matrigel. Serum-free media supplemented with several concentrations of W-13 or media with 10 $\%$ serum was placed in the bottom well. After 24 $\mathrm{h}$, the number of cells that invaded through the matrigel were calculated using fluorometric assay. For each cell line, the fluorometric reading from bottom wells with the serum-free media was defined as one unit to determine relative change in invasion in the presence of $10 \%$ serum. Each experiment contained one or two wells without serum and two wells with serum for each cell line. The experiment was repeated twice for MDA-MB-231 and MDA-MB-468.

\section{Statistical analysis}

Data were represented as mean \pm standard deviation ( ). Statistical analysis was carried out with one-way analysis of variance (ANOVA) and difference between groups was considered significant at $p<0.05$.

\section{RESULTS}

Effect of A-7, W-7 and W-13 on CD44/CD24 immunophenotypic subpopulations of MDA-MB-231 and MDA-MB-468

As shown in Figure 1, all calmodulin antagonists (A-7, W-7 and W-13) caused alterations in the subpopulation of the phonotypic CD44 + CD24of MDA-MB-231 cells. At lower concentrations $(20 \mu \mathrm{M})$, the percentages of the CD44 + CD24subpopulation were similar when subjected into the calmodulin antagonists of A-7, W-7 and W-13 as they were $75.36 \pm 2.34,65.44 \pm 7.5$ and 61.47 
\pm 4.9, respectively. However, when the concentrations of the antagonists were increased, there were some discrepancies in the percentages of the subpopulation of CD44+CD24-cells. As displayed in Figure 1a, the antagonist, A-7, caused reduction in the percentages of the expressed CD44+CD24- from $75.36 \pm 2.34$ to $38.63 \pm 5.7$ when the concentration of A-7 was enhanced from 20 to 60 $\mu \mathrm{M}$ but the percentages of CD44+CD24increased to $79.76 \pm 3.4$ and $77.97 \pm 5.6$ when the concentration was increased into 80 and 100 $\mu \mathrm{M}$, respectively.

On the other hand, both of $\mathrm{W}-7$ and $\mathrm{W}-13$ have caused reduction in the percentages of the expressed CD44+CD24- cells as their concentration increased from 20 to $100 \mu \mathrm{M}$ (Figures $1 \mathrm{~b}$ and $1 \mathrm{c}$ ). The antagonist, $\mathrm{W}-13$, was more potent than $\mathrm{W}-7$ as the percentages of CD44+CD24- cells were considerably reduced at different concentrations (40 -100 $\mu \mathrm{M})$ compared to $\mathrm{W}-7$. At $100 \mu \mathrm{M}, \mathrm{W}-7$ and $\mathrm{W}-13$ reduced the proportion of CD44 + CD24- to 30.27 and 0.44 , respectively.

Furthermore, the effect of $\mathrm{W}-7$ and $\mathrm{W}-13$ on CD44/CD24 immunophenotypic subpopulations of MDA-MB-468 cells was determined. It was observed that the expression of CD44+CD24when subjected to different concentrations of $\mathrm{W}$ $7\left(\begin{array}{lll}20 & -100 & \mu \mathrm{M}\end{array}\right)$ was zero and most of the expressed cells were the luminal CD44+CD24+ with a percentage of $99.54 \pm 0.12$ whereas the percentages of the CD44-CD24+ were in the range of 0.37-0.66. In contrast, the MDA-MB-468 cells administered different concentrations of $\mathrm{W}$ 13 revealed that the percentages of CD44+CD24- did not significantly differ as they were in the range of $0.1-0.27$ (Figure 2). Interestingly, as the concentration of W-13 increased, the percentages of the subpopulations of CD44+CD24+ decreased whereas the percentages of the subpopulations of CD44CD24+ increased.
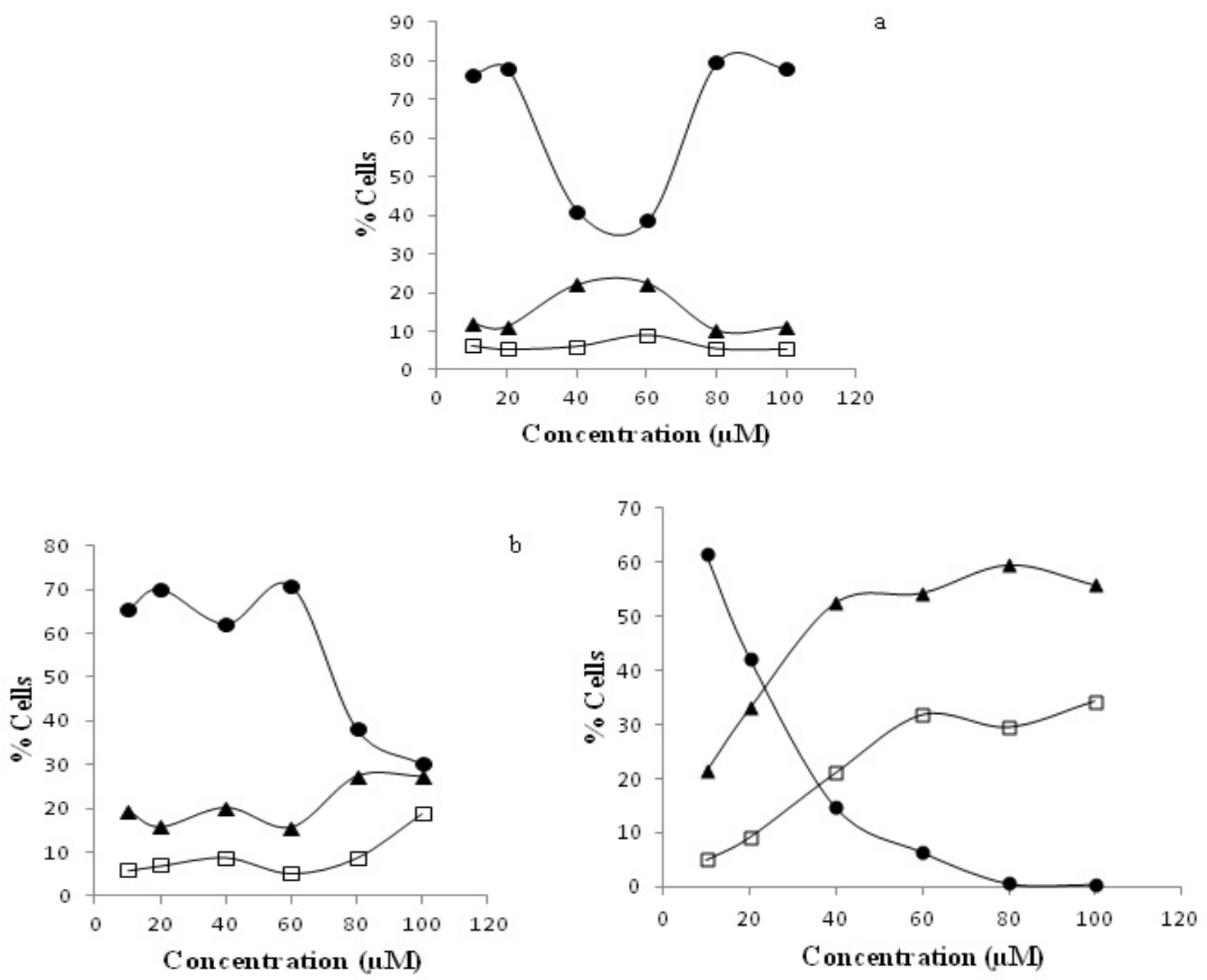

Figure 1: Effect of the calmodulin antagonists, (a) A-7, (b) W-7 and (c) W-13, on the subpopulations expression

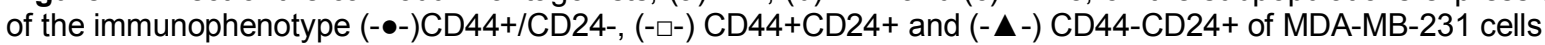




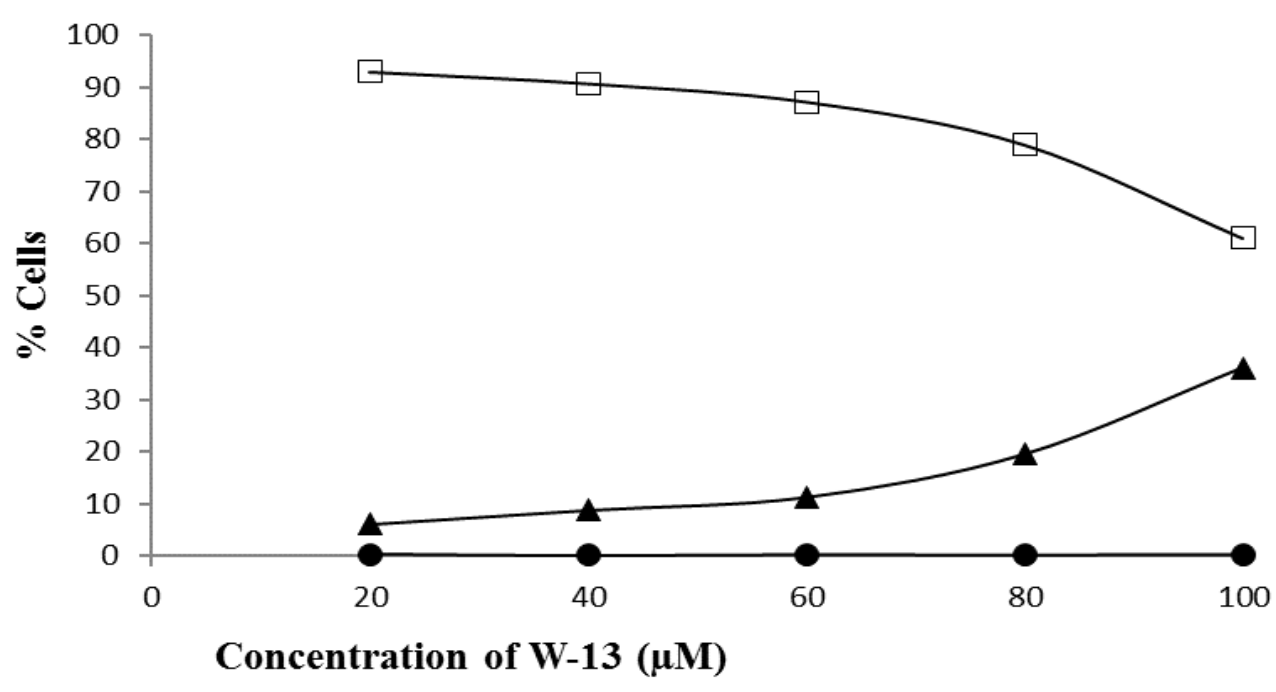

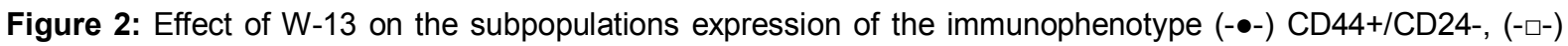
CD44+CD24+ and (- $\Delta-$ ) CD44-CD24+ of MDA-MB-468a

Effect of $\mathrm{W}-13$ on the invasive properties of CD44+CD24- of MDA-MB-231 and MDA-MB468 cells

Based on flow cytometry analysis, W-13 had a potential effect on the proportion of CD44+CD24of MDA-MB-231 and caused significant alterations in the subpopulation of CD44CD24 immunophenotypes of MDA-MB-468. As a consequence, further studies on the $\mathrm{W}-13$ effect on the invasive properties of MDA-MB- 231 and MDA-MB-468 were made. In Figure 3, the concentration of $\mathrm{W}-13$ was plotted against the mean relative fluorescence unit which correlated to the invasion properties of the cells. The invasion properties of MDA-MB-231 and MDAMB-468 cells were reduced as the concentrations of W-13 increased. However, the mean relative fluorescence units of MDA-MB-231 at all concentrations of $\mathrm{W}-13$ were significantly more than MDA-MB-468.

\section{DISCUSSION}

Calmodulin antagonists have antitumor activities against various cancers which could be explained by the role of calmodulin in raising the rate of cell growth and degree of tumor malignancy [12]. For example, W-7 has antiproliferative effect against skin cancer [13] and has the potential to suppress the expression of the MTS1 and NM23 genes in highly metastatic murine melanoma cells [14]. The anticancer effect of calmodulin antagonists could be due to impeding protein synthesis [15], stimulating apoptosis [16], or inhibiting angiogenesis [17].

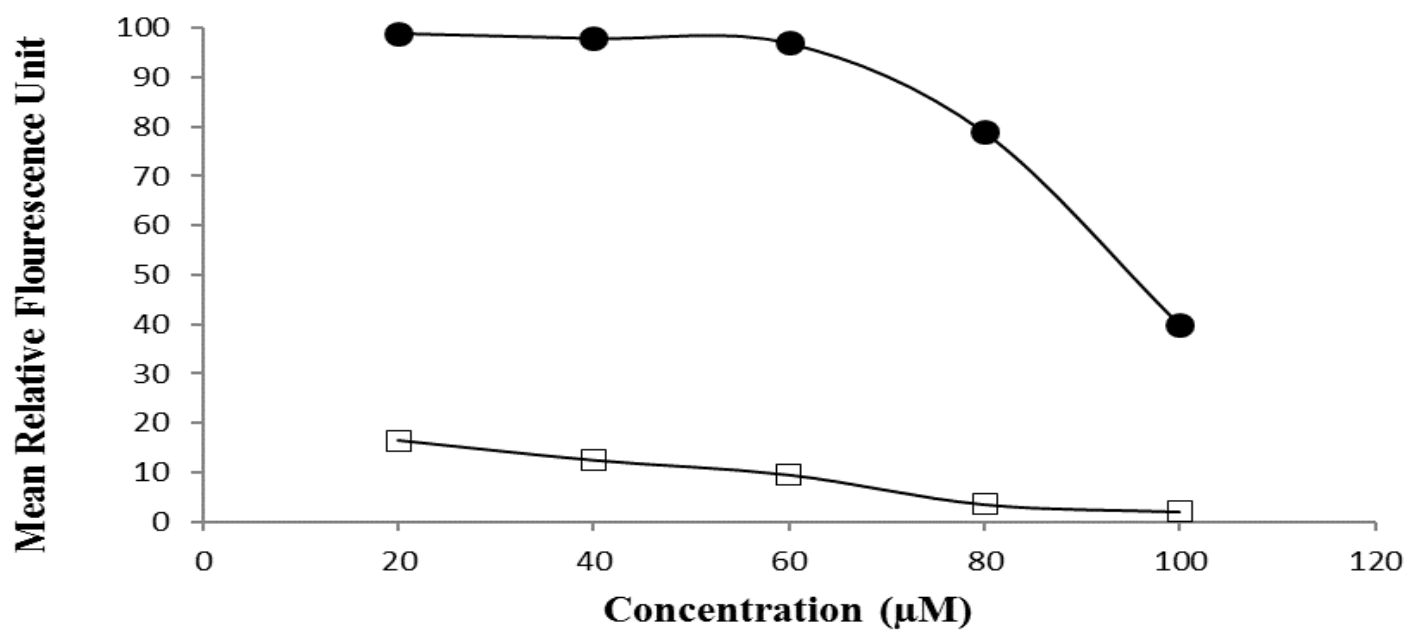

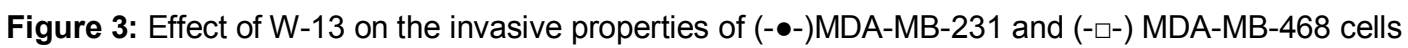


In 2003, Al-Hajj et al [1] were able to discriminate breast cancer cells based on their cell surface marker expression. They demonstrated that the cancer cells with the immunophenotype, CD44+CD24-, were able to initiate tumor whereas other phenotype populations, CD44+CD24+, CD44-CD24+, were nontumorigenic cancer cells. In this study, calmodulin antagonists, A-7, W-7 and W-13, were subjected MDA-MB-231 breast cancer cells in order to look for their effect on the proportions of the immunophenotype subpopulations of the breast cancer cells. Based on flow cytometry analysis, it has been found that $\mathrm{W}-13$ has the greatest inhibition effect on the expression of CD44+CD24-. In particular, $80 \mu \mathrm{M}$ of $\mathrm{W}-13$ was sufficient to reduce the proportion of CD44+CD24- from $61.47 \pm 4.9$ to $0.64 \pm 0.05 \%$. Furthermore, increasing the concentration of W13 lowered the proportion of the phenotype CD44+CD24+ and enhanced the proportion of CD44-CD24+ in MDA-MB-468 cells which resulted in reducing the invasive properties of the cells. Meyer et al [18] found that CD44+CD24+ cause local invasion by stimulating the expression of CD44+CD24- while CD44-CD24+ does not have effect on the metastatic properties of breast cancer cells.

\section{CONCLUSION}

Among the selected calmodulin antagonists, W13 had the greatest antitumor effect in both MDA-MB-231 and MDA-MB-468 cells. As the concentration of $\mathrm{W}-13$ increased, the proportion of CD44+CD24- in MDA-MB-231 significantly diminished whereas the proportion of CD44+CD24+ in MDA-MB-468 cells reduced. These alterations in the proportion of the subpopulations of CD44/CD24 immunophenotypes are consistent with the suppression of the invasive properties of MDA-MB-231 and MDAMB-468 cells.

\section{ACKNOWLEDGEMENT}

The authors wish to express sincere thanks and appreciation to King Abdulaziz University for financial support for this research project (no. 377/140/1432).

\section{REFERENCES}

1. Al-Hajj M, Wicha M, Morrison SJ, Clarke MF. Prospective identification of tumorigenic breast cancer cells. Proc Natl Acad Sci USA 2003; 100: 3983-3988.

2. Sheridan $C$, Kishimoto $H$, Fuchs $R$, Mehrotra $S$, BhatNakshatri $P$, Turner $C$, Goulet Jr R, Badve S, Nakshatri H. CD44+/CD24- breast cancer cells exhibit enhanced invasive properties: an early step necessary for metastasis. Breast Cancer Res 2006; 8:R59-R71.

3. Aigner S, Ramos CL, Hafezi-Moghadam A, Lawrence $M B$, Friederichs J, Altevogt $P$, Ley K. CD24 mediates rolling of breast carcinoma cells on $P$-selectin. FASEB J 1998; 12: 1241-1251.

4. Dimitroff CJ, Lee JY, Rafii S, Fuhlbrigge RC, Sackstein, R. CD44 is a major $E$ selectin ligand on human hematopoietic progenitor cells. J Cell Biol 2001; 153:1277-1286.

5. Pommier SJ, Quan GG, Christante D, Muller P, Newell $A E$, Olson SB, Diggs B, Muldoon L, Neuwelt $E$, Pommier RF. Characterizing the HER2/neu Status and Metastatic Potential of Breast Cancer Stem/Progenitor Cells. Ann Surg Oncol 2010; 17: 613-623.

6. Gunthert $U$, Hofmann M, Rudy W, Reber S, Zoller M, Haussmann I, Matzku S, Wenzel A, Ponta H, Herrlich P. A new variant of glucoprotein CD44 confers metastasis potential to rat carcinoma cells. Cell 1991; 65:13-24.

7. Charrad RS, Gadhoum Z, Qi J, Glachant A, Allouche M, Jasmin C, Chomienne C, Smadja-Joffe F. Effects of anti-CD44 monoclonal antibodies on differentiation and apoptosis of human myeloid leukemia cell lines. Blood 2002; 99, 290-299.

8. Gadhoum Z, Leibovitch MP, Qi J, Dumenil D, Durand L, Leibovitch S, Smadja-Joffe F. CD44: a new means to inhibit acute myeloid leukemia cell proliferation via P27Kip1. Blood 2004; 103, 1059-1068.

9. Fillmore CM, Kuperwasser C. Human breast cancer cell lines contain stem-like cells that self-renew, give rise to phenotypically diverse progeny and survive chemotherapy. Breast Cancer Res 2008, 10:R25R37.

10. Sionov RV, Naor D. Calcium- and calmodulin-dependent PMA-activation of the CD44 adhesion molecule. Cell Adhes Commun 1998; 6(6):503-523.

11. Gupta V, Zhang QJ, Liu YY. Evaluation of anticancer agents using flow cytometry analysis of cancer stem cells. Methods Mol Biol 2011; 716:179-191.

12. Berchtold M, Villalobo A. The many faces of calmodulin in cell proliferation, programmed cell death, autophagy, and cancer. Biochim Biophys Acta.2014; 1843: 398435

13. Nishino $H$, Iwashima $A$, Nakadate $T$, Kato $R$, Fujiki $H$, Sugimura T. Potent antitumor promoting activity of $N$ 6-aminohexyl)-5-chloro-1-naphthalenesulfonamide, a calmodulin antagonist, in mouse skin tumor formation induced by 7,12-dimethylbenz [a]anthracene plus teleocidin, Carcinogenesis 1984; 5 (2):283-285.

14. Ito $H$, Wang JZ, Shimura $K$. Inhibition of lung metastasis by a calmodulin antagonist, $N$-(6-aminohexyl)-5chloro-1-naphthalenesulfonamide (W-7), in mice bearing Lewis lung carcinoma, Anticancer Res 1991; 11: 249-252.

Trop J Pharm Res, August 2015; 14(8): 1397 
15. Kumar RV, Panniers R, Wolfman A, Henshaw EC. Inhibition of protein synthesis by antagonists of calmodulin in Ehrlich ascites tumor cells, Eur $J$ Biochem 1991; 195: 313-319.

16. Newton CJ, Eycott K, Green V, Atkin SL. Response of estrogen receptor containing tumour cells to pure antiestrogens and the calmodulin inhibitor, calmidzolium chloride, J Steroid Biochem Mol Biol 2000; 73(1-2):29-38.
17. Jung HJ, Kim JH, Shim JS, Kwon HJ. A novel $\mathrm{Ca}+$ +calmodulin antagonist $\mathrm{HBC}$ inhibits angiogenesis and down-regulates hypoxia-inducible factor, J Biol Chem 2010; 285: 25867-25874.

18. Meyer MJ, Fleming JM, Ali MA, Pesesky MW, Ginsburg $E$, Vonderhaar BK. Dynamic regulation of CD24 and the invasive, CD44posCD24neg phenotype in breast cancer cell lines. Breast Cancer Res 2009; 11:R82R95. 